\section{The secret is to have no secrets}

EARLIER this month, Anatolii Shcharanskii received a sentence of three years' imprisonment plus ten years' exile for divulging information officially classified by the Soviet authorities as "secret". According to the rumours routinely described as "reliable diplomatic sources", it would appear that much of this secret information was in fact a denial of secrecy. In his capacity as a human rights activist, Shcharanskii regularly brought to the notice of the foreign press details of Jewish scientists refused emigration visas on the grounds that they had been engaged in "secret" research.

The scientists, and Shcharanskii as their spokesman, fervently denied that their own work, or that of the institutes where they worked, was militarily sensitive. Nevertheless, to Soviet officialdom, it would appear that even to discuss matters of secrecy or otherwise is itself a breach of national security.

The "secrecy" of research is an argument frequently advanced by the Soviet authorities to explain why some Jewish scientist has not been allowed to emigrate to Israel. Since the notorious "education tax" on would-be emigrants was allowed to lapse some years ago, so that a departing scientist no longer had to repay the notional cost of his higher education, "secrecy" has been invoked so regularly as a barrier to emigration that it could appear to the outside observer that virtually all Soviet research may be classified as "secret".

Indeed, some statements by the Soviet authorities seem to point in that direction. When Vladimir Slepak, a refusnik cyberneticist, protested that his work could not possibly be secret, since the Soviet Union was at least five years behind the USA, it was explained to him that "that precisely is the secret".

During the 1976 Revolution Day celebrations, Moscow Radio claimed that it was meaningless for western campaigners to claim that such-and-

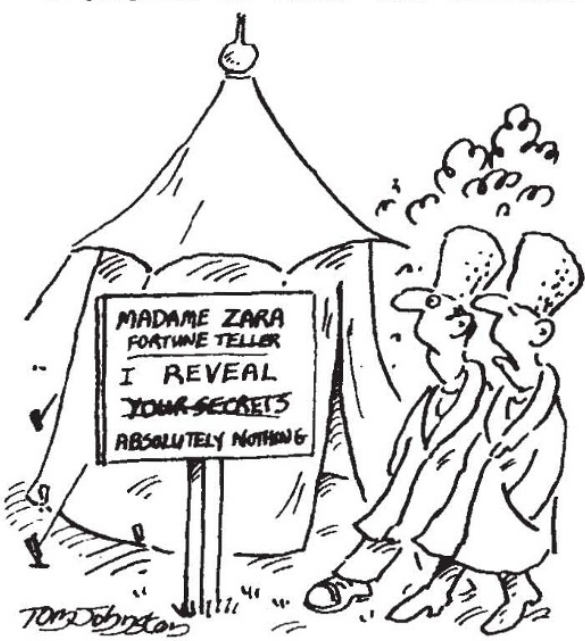

"I hear she wants to emigrate." such scientist had no access to secrets "since only we know what our secrets are"- and when no Western protests were forthcoming to what had seemed simply a routine propaganda broadcast, it was then intimated to CorrespondingAcademician Veniamin Levich that the West had clearly concurred with the Soviet Union on this point!

Access to military secrets is, indeed, considered by all human rights legislation a valid impediment to emigration. Normally, however, a reasonable term is set, after which the "secrets" are assumed to be obsolete or generally known. Some five to seven years would appear standard in most countries. The Soviet Union, however, sets far higher limits. Recently, Irina Brailovskaya (a mathematician) was told that her term of secrecy was for 30 years, of which five had already expired, while Aleksandr Lerner, a cyberneticist, was informed that his was "for life".

Normally, however, would-be emigrants not only are not told of how long they must wait for security clearance; they do not even have any means of knowing, short of applying for a visa, whether or not they are eligible to emigrate at all. Since application to emigrate routinely results in dismissal from one's post, for those whose jobs are so secret that they themselves are unaware of the secrecy, request for a visa can result in several years expiating their "secret" knowledge in the jobless limbo of the refusnik.

Vera Rich

None of the phenomena related are particularly new to investigators of the paranormal. The Kirlians were producing photographs, some two decades ago, which were claimed to show the energy fields of living organisms (and which, in the case of human subjects. showed "flares" at the traditional acupuncture points).

What is most remarkable about this latest claim of Zolotov is the support he regularly gets from TASS, first for his UFO/nuclear explanation of Tunguska, and now for his "biofield". Parapsychology, and its related phenomena, have always been a valid field of research in the Soviet Union. which has a vested atheistic interest in proving a physical basis for any phenomena which might otherwise be attributed to a nonmaterial "soul".

Nevertheless, one can only sympathise with Dr Peter Zolotov, Director of the Kirillin branch of the All-Union Geophysical Institute, where Zolotov officially works. Asked to comment on his subordinated work, Brodskii gave a non-committal answer. Zolotov's research he said, "seems to be interesting and promising". electromagnetic and gravitational fields. established, for example, that an "ailing thyroid gland" produces a biofield "in the shape of a dagger some 2 to 3 metres long". A healthy person sensitive to "biofields" can therefore, says Zolotov, restore normal functioning to the gland by influencing its biofield by his own.

Vera Rich 